\title{
Effect of grafting time on the success and survivability of different varieties of mango
}

\begin{abstract}
The aim of this experiment was to examine the effects of grafting time on the success and survivability of different varieties of mango. The study comprises nine grafting time, viz., 10, 20, 30 March, 10, 20, 30 April, 10, 20 and 30 May, 2009 and thirteen different varieties of mango viz. BAU Aam-1, 2, 3, 4, 5, 6, 7, 8, 9, 10, 11, 12, and BAU Aam-13 were used. The experiment carried out in the Randomized Complete Block Design with three replications. The maximum time required to bud breaking (12.14 days) was noted in 10 March grafted plants while the minimum (9.44 days) was obtained in the 30 April grafted plants. The highest percentages of graft success and survivability were recorded on 20 April $(96.87 \%$ and $90.62 \%)$ and the lowest was observed in 10 March grafting $(96.05 \%$ and $88.64 \%$ ). The minimum time (9.46 days) required for bud breaking was found in BAU Aam- 6 and the maximum (11.64 days) and was required in BAU Aam-10 followed by BAU Aam-13 (11.64days) and BAU Aam-12 (11.57days). The highest graft success and survivability (97.3\% and $96.23 \%$ ) were observed in BAU Aam-6 and the lowest $(95.66 \%$ and $86.42 \%)$ were in BAU Aam-13. In case of combined effect, the minimum time (7.73 days) was required in BAU Aam-6 in 30 April grafting while the maximum time (13.06 days) required for bud breaking was found in BAU Aam -10 when the grafting operation was done on 10 March. Grafting operation done on 10 April and 20 April with the scion of BAU Aam-1 gave the highest success (97.64\%) and the lowest (94.81\%) was on 10 March with BAU Aam-7. Grafting operation done on 10 April and 20 April with the scion of BAU Aam-6 gave the highest graft survivability $(96.56 \%)$ and the lowest $(71.66 \%)$ was on 10 March with BAU Aam-11.
\end{abstract}

Keywords: propagation, grafting process, success rate, yield
Volume 3 Issue 5 - 2019

\author{
Mst Girin Akter Khushi,' Md Touhiduzzaman \\ Sarker, ${ }^{2}$ Md Shahidul Islam, ${ }^{3}$ Sarder Md \\ Shahriar Alam ${ }^{4}$ \\ 'Department of Horticulture, Bangladesh Agricultural University, \\ Bangladesh \\ ${ }^{2}$ Department of Poultry Nutrition and Feed Science, Yangzhou \\ University, China \\ ${ }^{3}$ Department of Plant Pathology, Yunnan Agricultural University, \\ China \\ ${ }^{4}$ Department of Agricultural Chemistry, Bangladesh Agricultural \\ University, Bangladesh
}

Correspondence: Md Shahidul Islam, Department of Plant Pathology, Yunnan Agricultural University, Kunming, China, Email islam_ynau@I63.com

Received: August 07, 2019 | Published: October 03, 2019

\section{Introduction}

As a popular fruit, Mango (Mangifera indica L.) is being cultivated in this sub-continent since 4000 years ago. Mango originated in Indian sub-continent during the pre-historic times. ${ }^{1}$ It is grown in wide geographical area particularly in India, Pakistan, Brazil, Mexico, the Philippines, Indonesia, Thailand and Srilanka. ${ }^{1}$ Mango ranks third among the tropical fruits grown in the world with the total production of 25563 thousand metric tons. ${ }^{2}$ In Bangladesh, it occupies an area of about 31,278 hectares, with the production of 802750 metric tons of fruits and average yield of 25.66 tons per hectare. ${ }^{3}$ Mango is grown almost in all the district of Bangladesh, but it is extensively cultivated in Rajshahi, Dinajpur, Rangpur, Kushtia and Jessore. ${ }^{2}$ In all other districts mangoes are found to grow mostly from seeded plants in a sporadic manner only in the homestead areas. ${ }^{4-7}$

Mango is well accepted to the people all over the world for its special organoleptic features such as excellent flavor, pleasant aroma, attractive color and taste. ${ }^{8-11}$ The immature and unripe fruits are largely used for culinary purposes as well as preparation of pickles, chutneys etc which can be stored and consumed throughout the year. ${ }^{12,13}$ The good quality ripe mangoes are sold in the market at high price. ${ }^{14}$ Beside these mangoes are exported and largely used in the processing industry for processed products like mango bar, juice, squash, leather etc. ${ }^{15}$ It is a source of a number of vitamins (especially vitamin A and C), minerals and total soluble solids. ${ }^{16}$ It is also a medium source of carbohydrates (16.9\%). The minimum dietary requirement of fruit per head per day is $85 \mathrm{~g}$ whereas the availability is only $30-35 \mathrm{~g}$, which is much lower than the recommended daily requirement. ${ }^{17,18}$ Mango can be cultivated by both sexual and asexual (vegetative) methods but the vegetative method is better to retain the characteristics of the mother plant. ${ }^{19,20}$

The existing mango varieties particularly seeded ones are mostly tall in nature with a large canopy. But in Bangladesh the orchard areas are gradually decreasing day by day with the increase of population and required infrastructures. ${ }^{12,21}$ So it is difficult to incorporate tall and large canopy sized mango varieties in those areas. Varietal purity cannot be maintained in those plants raised from seeds. ${ }^{22}$ But grafted mango plants are true-to-type, require small area and start bearing earlier than the plants raised from seeds. ${ }^{20-23}$ Cleft grafting being the modern method is reported to be successfully practiced. Cleft grafting is easier than veneer grafting with $81.67 \%$ success and $67.92 \%$ survivability of grafts. Different factors influence the success, survivability and growth of mango grafts among which grafting method and varieties play vital role. ${ }^{24}$

Time of grafting operation has a great influence on the success of grafting in mango. ${ }^{11}$ Optimum time of operation depends mainly on environmental conditions and age of scion and rootstock. ${ }^{25}$ Various factors influence the success and survivability of mango grafts viz. varieties, time of grafting operation, grafting method, defoliation period of scion, age of the scion, leaf and node retention on rootstock. Among these, varieties and time of operation are important factors for higher success, survivability and growth of grafts. ${ }^{26}$ Information regarding the influence of time of grafting on the success of different varieties of mango is inconclusive. ${ }^{27}$ 
Considering these facts the present piece of research work was undertaken to study the effect of varieties and time of grafting on success and survivability in mango with following objectives:

To find out the suitable variety for maximum graft success and survivability;

To determine the appropriate time of grafting for the highest percentage of graft success and survivability;

To study the interaction effect of variety and the time of grafting for highest success and survivability of grafts.

\section{Materials and methods}

This section deals with the materials used and methodology followed in conducting the experiment. The location of the experiment, climate, materials used and methods followed in different operations during the experiment as well as in data collection are described here under the following sub-heads.

\section{Experimental site}

The present experiment was conducted at the 'BAU Germplasm Centre'(GPC) of Fruit Tree Improvement Program (FTIP), Department of Horticulture, Bangladesh Agricultural University (Figure 1) during the period from August, 2008 to January, 2009.

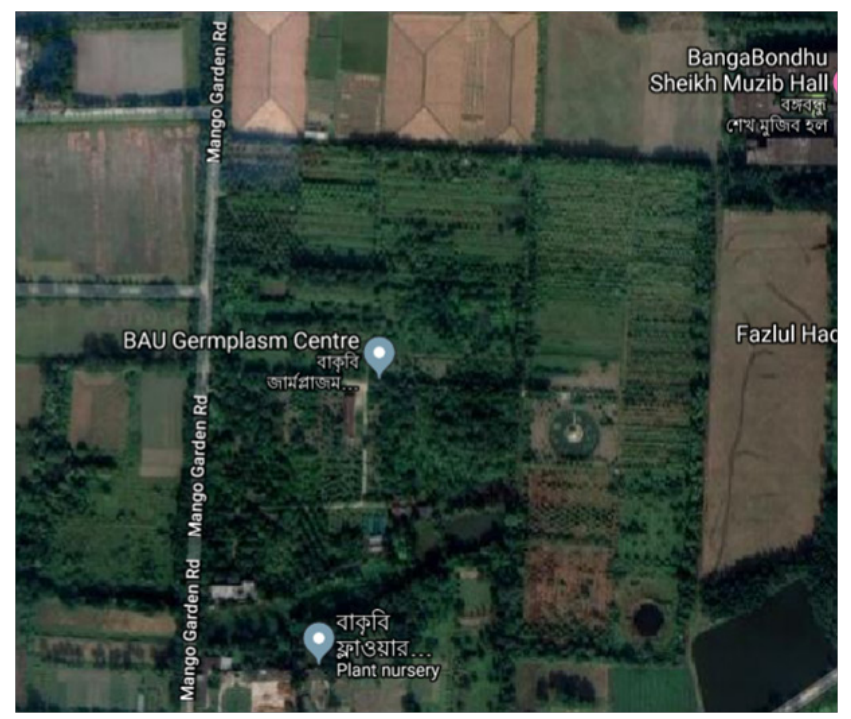

Figure I GPS location of BAU Germplasm centre.

\section{Climate and soil}

The experimental area is situated under the sub-tropical monsoon climate, which is characterized by high temperature and heavy rainfall during the months of April to September and scanty rainfall associated with moderately low temperature during the rest period of the year. ${ }^{28}$ The total rainfall of the locality was $653.9 \mathrm{~mm}$ during the period from August, 2008 to January, 2009. The average temperature during the period of experiment was $24.66^{\circ} \mathrm{C}$. The average humidity observed from August to January, was around $86.52 \%$. The soil of the experimental area was silt loam in texture belonging to the Old Brahmaputra Flood Plain of AEZ 9 having non-calcareous Dark Grey Flood Plain soil. The selected area was a medium high land. It was fertile and well drained and slightly acidic with the $\mathrm{pH}$ varying from 5.5 to 6.8 .

\section{Experimental materials}

Experimental materials were scion of thirteen mango varieties released from GPC-BAU. The scions were collected from the mother plants of thirteen mango varieties released from Germplasm Centre of fruit Tree Improvement Project (FTIP), Department of Horticulture, Bangladesh Agricultural University.

\section{Treatment of the experiment}

The experiment consisted of two factors with nine treatment combinations:

Factor-A: Time of grafting operation

Nine dates of grafting operation were considered viz.

$\mathrm{T}_{1}=10$ March ( $1^{\text {st }}$ time of grafting)

$\mathrm{T}_{2}=20$ March ( $2^{\text {nd }}$ time of grafting)

$\mathrm{T}_{3}=30$ March ( $3^{\text {rd }}$ time of grafting)

$\mathrm{T}_{4}=10$ April ( $4^{\text {th }}$ time of grafting)

$\mathrm{T}_{5}=20$ April ( $5^{\text {th }}$ time of grafting $)$

$\mathrm{T}_{6}=30$ April ( $6^{\text {th }}$ time of grafting)

$\mathrm{T}_{7}=10$ May ( $7^{\text {th }}$ time of grafting)

$\mathrm{T}_{8}=20$ May $\left(8^{\text {th }}\right.$ time of grafting $)$

$\mathrm{T}_{9}=30$ May $\left(9^{\text {th }}\right.$ time of grafting $)$

Factor-B: Mango varieties

$\mathrm{V}_{1}=$ BAU Aam -1 (Sraboni-1)

$\mathrm{V}_{2}=$ BAU Aam -2 (Seedless)

$\mathrm{V}_{3}=$ BAU Aam -3 (Diabetic)

$\mathrm{V}_{4}=$ BAU Aam -4 (Rad)

$\mathrm{V}_{5}=$ BAU Aam -5 (Sraboni-2)

$\mathrm{V}_{6}=$ BAU Aam -6 (Polyembryoni-1)

$\mathrm{V}_{7}=$ BAU Aam -7 (Polyembryoni-2)

$\mathrm{V}_{8}=$ BAU Aam -8 (Polyembryoni-3)

$\mathrm{V}_{9}=$ BAU Aam -9 (Shoukhin-1)

$\mathrm{V}_{10}=$ BAU Aam -10 (Shoukhin-2)

$\mathrm{V}_{11}=$ BAU Aam -11 (Kanchamitha-1)

$\mathrm{V}_{12}=$ BAU Aam -12 (Kanchamitha-2)

$\mathrm{V}_{13}=$ BAU Aam -13 (Kanchamitha-3)

\section{Design and layout of the experiment}

The two-factor experiment consisting of one hundred seventeen treatment combinations laid out in Randomized Complete Block Design (RCBD) with three replications. For each treatment combination grafting operations were performed on rootstocks. Thus in total $3510(9 \times 13 \times 3 \times 10)$ grafts were made.

\section{Preparatory works for grafting}

According to the design and objectives of the experiment the following works were done 
1. Selection of rootstock

2. Selection of scion mother plants for scion collection

3. Selection and collection of scion materials

4. Date of grafting to be done

For the above operations, different tools and accessories were used such as grafting knife, secateurs, polythene strip, polythene sheet and poly cap and shading materials.

\section{Selection of rootstocks, mother plants and scion collection}

Nearly 8-11 months old seedling rootstocks of unknown cultivars of mango raised in the nursery beds at the BAU Germplasm Center (GPC) were used in this experiment. These seedlings, which were healthy, vigorous, pest and disease free and uniform in size and growth were selected for the experiment. Selection of scion mother plant is the important factors for the propagation of fruit plants by grafting. Quality scion mother plant with appropriate growing conditions assure higher percentage of graft success. Considering this fact, pest and disease free, healthy, and uniform bearing 4-5 years old scion mother plants of mango varieties were selected. Scion is the key factor in successful vegetative propagation of fruit plant. Quality scion with appropriate growing conditions assures higher percentage of graft success. Therefore, the non-flowering shoots of fresh growth having dark green colored leaves, about $15 \mathrm{~cm}$ long, straight, smooth, healthy, pest and disease free with swollen terminal bud in bulky condition and also of same thickness of rootstock were selected. The scion shoots were of about 3-4 months old containing sufficient reserved food materials, which was necessary for respiration, callus formation and successful graft union. The selected scion shoots were detached from the mother plants with the help of sharp secateurs and were defoliated leaving one-fourth of the petiole just before grafting. The collected scion shoots were then carried in a poly bag to the experimental plots and kept in shady or cool place to avoid desiccation.

\section{Grafting operation}

Cleft grafting is one of the simplest and easiest methods and largely used in propagation of mango. It is used in top working for changing varieties and also in producing planting materials. In this method about $3-4 \mathrm{~cm}$ long two smooth slanting cuts were made at the proximal end of the scion on both sides opposite to each other in such a way that the end portion became very thin. It was done with the help of sharp knife. The smooth long slopping wedge cuts at the base of the scion gave an appearance of a sharp chisel. The rootstock was at first deheaded by giving horizontal cut and then a vertical split cut or cleft was made by a thin and sharp bladed grafting knife at the center of the horizontal cut surface of the stock having a depth of approximately $3-4 \mathrm{~cm}$. Then, the scion was inserted into the cleft of rootstock through slight opening the splits. Thus both components were brought into close contact particularly cambium in face to face and tied firmly with polythene strip. After wrapping the graft union, the scion along with the union portion was covered with a polythene cap to protect the scion from loss of moisture through transpiration. In this method, both the stock and scion were of same thickness to match each other. The grafting operations were done at per time schedule of the treatment.

\section{Intercultural operations and after care}

All necessary measures were adopted to make the plot free from weeds and create a favorable environment to ensure proper growth and development of the grafted plants. Weeding and mulching were done whenever necessary during the period of investigation. The channels, made around each plot were connected to the main drain for rapid removal of excess rainwater. Proper shades were provided with the help grafting shade mates until the grafts were in good condition in growth. Sometimes the shade was removed to expose the plant to the direct sunlight for their proper growth.

Water, carbon dioxide and heat accumulated in poly cap through transpiration and respiration were removed by opening the poly caps for a few second at an interval of three days from the date of grafting. After about 20-25 days of grafting, sprouts/off shoots began to develop from the node below the graft union of the rootstock. These off shoots were immediately removed after their initiation as these off shoots could adversely affect the success of union as well as the growth of the grafts. Side dressing after maturation of first flash leaves was done with Urea and MOP for proper growth and development of grafts. When the grafts were found to produce new flushes (light green) of growth at their terminal end, the covering poly caps were removed from the grafts. Within 9-12 days the successful grafts started to produce new leaves. Polythene strips, used for wrapping the graft joint, were removed after 2 months of grafting for the better growth and development of graft. As a preventive measure against insect pest and diseases, spraying with insecticides and fungicides were done following a routine schedule. For this, Sumithion and Dithane $\mathrm{M}-45$ at the rate of $2 \mathrm{ml} /$ litre were applied at $7-10$ days interval from two to three weeks after grafting and continued up to the last date of recording final data.

\section{Data collection}

The data on different parameters were recorded at one-month interval except the times required bud breaking, first flash, first leaf opening, percentage of graft success and percentage of graft survivability. The data were collected on the following parameters:

The emergence of bud of the grafts as influenced by varieties and time of grafting were observed critically and data were collected in every day. The days required to bud breaking from the date of grafting was taken periodically. From them average time required to bud breaking was calculated.

The numbers of successful grafts in each treatment were counted at 10 days interval up to 120 days after grafting. Emergence of shoot from the terminal bud of scion was considered as the success of a graft. Results were calculated and expressed in percentage basis. Percentage of successful grafts of individual treatment was calculated by using the following formula:

$$
\text { Percentage of graft success }=\frac{\text { Number of successful grafts }}{\text { Total number of grafted rootstock }} \times 100
$$

After 40 days of initial success, the grafts were observed for next five months and in some successful grafts, some scions were found to die. The number of grafts survival was recorded and percentage of survival was calculated by using the following formula:

$$
\text { Percentage of graft survival }=\frac{\text { Total number of graft done-Total number of death scion after grafting }}{\text { Total number of graft done }} \times 100
$$

The total height was recorded at the time of grafting operation. Increased increased stionic height of successfully grown up graft was measured at 30 days interval starting from $30 \mathrm{DAG}$ with the help of 
measuring scale from the ground level to the apex of the terminal bud to scion and was expressed in $\mathrm{cm}$ (centimeter). Increased length of scion per graft was calculated by the following formula:

Increased length of rootstock $=$ Height up to terminal bud of successful graft during growth- Initial height up to terminal bud of scion at the time of grafting operation

The total number of new leaves per graft was counted at an interval of 30 days starting from 30 days after each grafting and was continued up to 120 days. The number of leaves per graft was calculated as a cumulative number. Increased length of rootstock was recorded in centimeter $(\mathrm{cm})$ on the date of grafting operation. Increased length of rootstock per successful graft was recorded at 30 days interval from 30 days after grafting operation and was continued up to 120 DAG. Increased length of rootstock was calculated by the following formula:

Increased length of rootstock $=$ Total length of rootstock during growth of graft - Initial length of rootstock at the time of grafting operation

Increased length of scion per successful graft was recorded incm from the middle portion the graft joint up to the tip of the longest shoot at 30 days interval starting from 30 days after grafting operation and was continued up to 120 days. Increased length of scion per graft was calculated by the following formula:

Increased scion length $=$ Total length of scion during growth of graft - Initial length of scion at the time of grafting operation

\section{Statistical analysis}

The collected data on the different parameters of study were statistically analyzed to find out the significance of differences between the treatments and treatment combinations. The means of all the treatments were calculated and the analyses of variances (ANOVA) for all the characters were performed by ' $F$ ' variance test. The significance of differences between treatments means were compared by Least Significant Difference (LSD) test.

\section{Results and discussion}

\section{Effect of time of grafting operation}

Main effect of time of grafting operation: Days required to bud breaking in different time of grafting as presented in Appendix-II was significant at $1 \%$ level of probability. The results on the days required to bud breaking influenced by the time of grafting operation have been presented in Table 1. The minimum time required to bud breaking $(9.44$ days) for 30 April followed by 10 May ( 9.45 days) grafted plants while it was noted maximum (12.14 days) was in 10 March grafted plants followed by 20 March (11.27) and 30 March (11.47) The earliest bud breaking in 30 April might be due to the favorable environmental conditions prevailed at that time.

\section{Main effect of varieties}

The present study revealed that there was significant effect of varieties on the days required to bud breaking (Appendix-II). The minimum time (9.46days) required for bud breaking was found in BAU Aam- 6 followed by BAU Aam-7 (9.72days) and the maximum (11.64 days) and was required in BAU Aam-10 followed by BAU Aam-13 (11.64days) and BAU Aam-12 (11.57days) (Table 2). This variation in time required for bud breaking may be due to varietal characters of mango.
Table I Main effect of time of grafting operation

\begin{tabular}{llll}
\hline Date & $\begin{array}{l}\text { Days required to } \\
\text { bud breaking }\end{array}$ & \% Success & \% Survivability \\
\hline I0-Mar & 12.14 & 96.05 & 88.64 \\
20-Mar & 11.27 & 96.23 & 89.93 \\
30-Mar & 11.47 & 96.43 & 90.13 \\
I0-Apr & 10.32 & 96.81 & 90.51 \\
20-Apr & 10.32 & 96.87 & 90.62 \\
30-Apr & 9.44 & 96.61 & 90.35 \\
I0-May & 9.45 & 96.59 & 90.28 \\
20-May & 10.27 & 96.61 & 90.36 \\
30-May & 11.64 & 96.15 & 90.02 \\
LSD at 5\% & 0.068 & 0.014 & 1.209 \\
LSD at I\% & 0.089 & 0.019 & 1.607 \\
Level of & $* *$ & $* *$ & $* *$ \\
significance & & & \\
\hline
\end{tabular}

**= Significant at $1 \%$ level of probability

Table 2 Main effect of varieties

\begin{tabular}{|c|c|c|c|}
\hline Variety & $\begin{array}{l}\text { Days required to } \\
\text { bud breaking }\end{array}$ & \% Success & \%Survivability \\
\hline BAU Aam-I & 10.45 & 96.83 & 90.78 \\
\hline BAU Aam-2 & 10.73 & 96.44 & 88.82 \\
\hline BAU Aam-3 & 10.58 & 96.93 & 92.82 \\
\hline BAU Aam-4 & 10.81 & 96.05 & 87.47 \\
\hline BAU Aam-5 & 10.54 & 96.76 & 90.46 \\
\hline BAU Aam-6 & 9.46 & 97.3 & 96.23 \\
\hline BAU Aam-7 & 9.72 & 96.7 & 94.97 \\
\hline BAU Aam-8 & 10.07 & 96.95 & 93.8 \\
\hline BAU Aam-9 & 10.73 & 96.69 & 89.38 \\
\hline BAU Aam- I0 & II.65 & 95.9 & 86.67 \\
\hline BAU Aam-II & 11.2 & 96.33 & 86.78 \\
\hline BAU Aam- I 2 & 11.57 & 95.79 & 86.61 \\
\hline BAU Aam-I 3 & 11.64 & 95.66 & 86.42 \\
\hline LSD at $5 \%$ & 0.081 & 0.017 & 1.453 \\
\hline LSD at I\% & 0.107 & 0.022 & 1.932 \\
\hline $\begin{array}{l}\text { Level of } \\
\text { significance }\end{array}$ & $* *$ & $* *$ & $* *$ \\
\hline
\end{tabular}

$* *=$ Significant at $\mathrm{I} \%$ level of probability

\section{Combined effect of time of grafting operation and varieties}

Days required to bud breaking was significantly influenced by the combined effect of varieties and time of grafting operation and varieties of mango. The minimum time ( 7.73 days) was required in BAU Aam-6 in 30 April grafting while the maximum time (13.06 days) required for bud breaking was observed in BAU Aam -10 when the grafting operation was done. 


\section{Effect of time of grafting operation and varieties on graft success}

\section{Main effect of time of grafting operation}

The percentage of grafting success was significantly influenced by the different time of grafting operations and that was varied from $96.05 \%$ to $96.87 \%$ (Table 2). The highest success in grafting was recorded in 20 April (96.87\%) followed by 10 April (96.81\%). The lowest graft success was observed in 10 March (96.05\%) followed by 20 March (96.23\%) grafting operation. This difference in success might be due to the prevalence of varied climatic conditions at the time of grafting operation. The highest success in 20 April was also probably due to availability of dormant scion with swollen bud in bulging condition at that time.

\section{Main effect of varieties}

The data showed that the varieties had significant effect on the success of grafting which was recorded at 60 DAG. The highest graft success $(97.30 \%)$ was achieved in BAU Aam-6 followed by BAU Aam- 8 $(96.95 \%)$ and the lowest (95.66) was in BAU Aam-13 followed by BAU Aam-12 (95.79\%) (Table 2). The variation of success of grafting may be due to environmental condition. In BAU Aam -6 the cambial activity is higher which helps the success of grafting operation.

\section{Combined effect of varieties and time of grafting on percentage of graft success}

The combined effect of time of grafting operation and varieties on the percentage of success was found to be significant. Grafting operation done in 10 April and 20 April with the scion of BAU Aam-1 gave the highest success $(97.64 \%)$ followed by 10 April and 20 April with the scion of BAU Aam-7 (97.47\%) and the lowest (94.81\%) was in 10 March with BAUAam-7 followed by 30 May with the scion of BAU Aam-7 (94.91\%). This variation might be due to the supply of photosynthesis and other growth factors that were necessary to influence cambial activity and subsequent grafting success.

\section{Effect of time of grafting operation and varieties on} graft survivability

\section{Main effect of time of grafting}

The percentage of grafting survivability was significantly influenced by the different time of grafting operation and that was varied from 88.64 $\%$ to $90.62 \%$ (Table 1 ). The highest survivability in grafting operation was recorded in 20 April (90.62\%) operation followed by 10 April (90.51\%). The lowest graft survivability was observed in 10 March (88.64\%) grafting operation. followed by 20 April (89.93\%). This difference in survivability might be due to the prevalence of varied climatic conditions at the time of grafting operation. The highest survivability in 20 April was probably due to favorable climatic conditions that helped in quick vascular condition.

\section{Main effect of varieties}

The present study revealed that there was significant effect of varieties on the percentages of graft survivability. The maximum graft survivability $(96.23 \%)$ was observed in BAU Aam- 6 followed by BAU Aam-7 (94.97\%) (Table 2). The minimum (86.42\%) was found in BAU Aam-13 followed by BAU Aam-12 (86.61\%). This variation in time on the percentages of graft survivability may be due to varietal characters of mango.

\section{Combined effect of varieties and time of grafting on graft survivability}

The combined effect of grafting time and varieties on the percentage of graft survivability was found to be significant. Grafting operation done in 10 April and 20 April with the scion of BAU Aam-6 gave the highest graft survivability $(96.56 \%)$ and the lowest $(71.66 \%)$ was in 10 March with BAU Aam-11. This variation might be due to the supply of photosynthesis and other growth factors that were necessary to influence cambial activity and subsequent grafting survivability.

\section{Effect of time of grafting and varieties on increased stionic height}

Increased stionic height due to the effects of treatments was measured periodically during the entire period of study. The mean increase in stionic height at every date of measuring was calculated. The analysis of variance showed a significant variation $(\mathrm{P}<0.01)$ due to the differences in time of grafting operation and varieties

\section{Main effect of time of grafting operation}

The increased stionic height was found to be statistically significant (Table 3) at every date of data recording due to the effect of time of grafting operation. After 120 days of grafting, maximum increased stionic height $(66.16 \mathrm{~cm})$ was recorded in case of 20 April operation, while the minimum $(65.07 \mathrm{~cm})$ was in 10 March operation. The second highest increased stionic height $(66.14 \mathrm{~cm})$ was found in 10 April grafted plants. This might be due to favorable climatic condition, which accelerated early bud break and thus secondary affect on maximum increased stionic height.

Table 3 Main effect of time of grafting operation on increased stionic

\begin{tabular}{lllll}
\hline \multirow{2}{*}{ Date } & \multicolumn{4}{l}{ Increased stionic height $(\mathbf{c m})$ at } \\
\cline { 2 - 5 } & 30 DAG & 60 DAG & 90 DAG & I 20 DAG \\
\hline I0-Mar & 27.14 & 35.6 & 55.19 & 65.07 \\
20-Mar & 26.4 & 35.5 & 55.12 & 65.56 \\
30-Mar & 26.6 & 35.7 & 55.32 & 65.76 \\
I0-Apr & 26.98 & 36.08 & 55.7 & 66.14 \\
20-Apr & 26.98 & 36.13 & 55.71 & 66.16 \\
30-Apr & 26.88 & 35.9 I & 55.38 & 65.9 \\
I0-May & 26.64 & 35.67 & 55.38 & 65.76 \\
20-May & 26.72 & 35.87 & 55.45 & 65.9 \\
30-May & 27.19 & 35.65 & 57.26 & 65.1 \\
LSD at 5\% & 0.541 & 0.357 & 0.969 & 0.363 \\
LSD at I\% & 0.713 & 0.47 & 1.278 & 0.479 \\
Level of significance & $* *$ & $* *$ & $* *$ & $* *$ \\
\hline
\end{tabular}

$* *=1 \%$ level of probability, DAG = Days after grafting

\section{Main effect of varieties}

Varietal effect significantly influenced on the increased stionic height at all DAG. The highest increased stionic height $(79.14 \mathrm{~cm})$ was observed in BAU Aam-6 at 120 DAG and the lowest increased stionic height $(60.19 \mathrm{~cm})$ was in B A U A a m-13 ( Table 4). 
Table 4 Main effect of varieties on increased stionic height

\begin{tabular}{lllll}
\hline \multirow{2}{*}{ Variety } & \multicolumn{4}{c}{ Increased stionic height $(\mathbf{c m})$ at } \\
\cline { 2 - 5 } & 30 DAG & 60 DAG & 90 DAG & I 20 DAG \\
\hline BAU Aam-I & 28 & 36.5 & 55.47 & 65.2 \\
BAU Aam-2 & 26.36 & 34.97 & 54.05 & 63.93 \\
BAU Aam-3 & 29.65 & 38.59 & 58.24 & 68.53 \\
BAU Aam-4 & 24.93 & 33.86 & 52.38 & 61.58 \\
BAU Aam-5 & 27.76 & 36.13 & 54.92 & 65.04 \\
BAU Aam-6 & 33.05 & 44.5 & 64.07 & 79.14 \\
BAU Aam-7 & 30.57 & 40.7 & 59.98 & 73.45 \\
BAU Aam-8 & 30.7 & 38.63 & 60.15 & 68.7 \\
BAU Aam-9 & 27.63 & 35.28 & 54.84 & 64.01 \\
BAU Aam-10 & 21.5 & 29.83 & 50.5 & 60.25 \\
BAU Aam-II & 24.44 & 34.49 & 56.57 & 62.92 \\
BAU Aam-12 & 22.7 I & 32.5 & 51.36 & 61.27 \\
BAU Aam-3 & 21.61 & 29.29 & 50.43 & 60.19 \\
LSD at 5\% & 0.65 & 0.429 & 1.165 & 0.436 \\
LSD at I\% & 0.856 & 0.565 & 1.536 & 0.575 \\
Level of significance & $* *$ & $* *$ & $* *$ & $* *$ \\
\hline
\end{tabular}

$* *=1 \%$ level of probability, DAG = Days after grafting

\section{Combined effect of time of grafting and varieties on stionic height}

The combined effect of time of grafting operation and varieties on the increased stionic height was found to be significant at 30 to 120 DAG. These results indicated that the variation in increased stionic height might be due to cumulative effect of time of grafting operation and varieties or either varieties or time of grafting operation. Considering both varieties and times of grafting operation, the combined effect was highly significant. The highest increase in stionic height $(79.48 \mathrm{~cm})$ was noticed in grafts when grafting operation was done in 20 April with the scion of B A U A am 6, which was followed by 20 May operation with B AU A Am-7 $(59.83 \mathrm{~cm})$. On the other hand, 10 March operations with BAU Aam-10 observed to have the lowest increased stionic height $(59.75 \mathrm{~cm})$.

\section{Effect of time of grafting and varieties on number of new leaves}

\section{Main effect of time of grafting operation}

The number of leaves of new growth was found to be statistically significant (Table 5) at every date of data recording due to the effect of time of grafting operation. After 120 days of grafting operation, maximum number of leaves (22.63) was recorded in case of 20 April operation, while the minimum (21.15) was in 10 March. The second highest number of leaves (22.42) was found in 10 May grafted plants. This might be due to favorable climatic condition, which accelerated early bud break and thus affected on maximum leaf emergence of new growth.

\section{Main effect of varieties}

The data showed that the varieties had significant effect on the production of new leaves which was recorded at 120 DAG. The highest leaf number (23.19) was produced by BAU Aam-7 followed by BAU Aam-6 (23.10) and the lowest (20.72) was in BAU Aam-10 followed by BAU Aam-13 (20.75) (Table 6).

Table 5 Main effect of time of grafting on new leaves

\begin{tabular}{lllll}
\hline \multirow{2}{*}{ Date } & \multicolumn{4}{l}{ Number of new leaves at } \\
\cline { 2 - 5 } I0-Mar & 30 DAG & $\mathbf{6 0}$ DAG & 90 DAG & I 20 DAG \\
20-Mar & 10.09 & 13.17 & 17.17 & 21.15 \\
30-Mar & 10.29 & 14.21 & 18.01 & 21.99 \\
I0-Apr & 10.67 & 14.59 & 18.59 & 22.19 \\
20-Apr & 10.7 & 14.62 & 18.62 & 22.63 \\
30-Apr & 10.46 & 14.36 & 18.35 & 22.33 \\
I0-May & 10.42 & 14.42 & 18.42 & 22.42 \\
20-May & 10.44 & 14.36 & 18.36 & 22.37 \\
30-May & 10.21 & 14.2 & 18.2 & 22.3 \\
LSD at 5\% & 0.049 & 0.065 & 0.068 & 0.121 \\
LSD at I\% & 0.064 & 0.085 & 0.089 & 0.16 \\
Level of significance & $* *$ & $* *$ & $* *$ & $* *$ \\
\hline ** I\% level of significance, DAG = Days after grafting &
\end{tabular}

Table 6 Main effect of varieties on new leaves

\begin{tabular}{|c|c|c|c|c|}
\hline \multirow{2}{*}{ Variety } & \multicolumn{4}{|c|}{ Number of new leaves at } \\
\hline & 30 DAG & 60 DAG & 90 DAG & I 20 DAG \\
\hline BAU Aam-I & 10.8 & $|4.5|$ & 18.53 & 22.51 \\
\hline BAU Aam-2 & 10.67 & 14.58 & 18.5 & 22.42 \\
\hline BAU Aam-3 & 10.87 & 14.86 & 18.85 & 22.74 \\
\hline BAU Aam-4 & 9.79 & 13.19 & 17.2 & 21.22 \\
\hline BAUAam-5 & 10.75 & 14.82 & 18.82 & 22.83 \\
\hline BAU Aam-6 & 10.98 & 15.02 & 19.06 & 23.1 \\
\hline BAU Aam-7 & 10.95 & 14.98 & 19.01 & 23.19 \\
\hline BAU Aam-8 & 10.94 & 14.97 & 19.01 & 23.04 \\
\hline BAU Aam-9 & 10.65 & $14.6 \mid$ & 18.56 & 22.52 \\
\hline BAU Aam- 10 & 8.81 & 12.78 & 16.75 & 20.72 \\
\hline BAU Aam-I I & 10.03 & 14.04 & 18.04 & 22.01 \\
\hline BAU Aam- I 2 & 9.69 & |3.7| & 17.72 & 21.74 \\
\hline BAU Aam- I 3 & 8.69 & 12.7 & 16.73 & 20.75 \\
\hline LSD at $5 \%$ & 0.059 & 0.078 & 0.081 & 0.146 \\
\hline LSD at I\% & 0.077 & 0.102 & 0.107 & 0.192 \\
\hline Level of significance & $* *$ & $* *$ & $* *$ & $* *$ \\
\hline
\end{tabular}

** $=1 \%$ level of significance, $D A G=$ Days after grafting

\section{Combined effect of varieties and time of grafting on new leaves}

There was significant variation in number of new leaves due to the combined effect of the factors employed in the experiment. The highest number of leaves (24.34) was produced when grafting operation was 
done on 30 May with the scion of BAU Aam-7 while it was the lowest (19.46) for the treatment combination of 10 March grafting operation with BAU Aam-13. This result envisaged that the number of leaves per graft was depended on the cumulative effect of the two factors.

\section{Main effect of time of grafting and varieties on rootstock length}

The increase in rootstock length for all assigned treatments was measured periodically giving 30 days' interval and continued up to 120 days after grafting. It was found that independently time of grafting operation and varieties significantly influenced $(\mathrm{P}<0.01)$ on the increase in rootstock length.

\section{Main effect of time of grafting operation}

The periodically recorded data on the increment of rootstock length envisaged that there was an ample influence of different time of operations on increased rootstock length. The 20 April operation showed the maximum growth that was closely followed by 10 April operation. The prevailing congenial climatic condition might be the reason. After 120 days of grafting operation, the highest rootstock length $(74.97 \mathrm{~cm})$ was found in 20 April grafted plants. The lowest rootstock growth was recorded in case of 10 March grafted plants $(73.86 \mathrm{~cm})$. The result might be due to the variation in environmental condition. ${ }^{29}$ As the extremity of either direction of temperature and humidity is harmful for normal growth and development of plants, thus the March and May grafted plants might have not performed better. ${ }^{30}$ However, the growth rate of the rootstock was seen in accordance with the raising in temperature and increased humidity. (Table 7). ${ }^{31}$

Table 7 Main effect of time of grafting on increased length of rootstock

\begin{tabular}{lllll}
\hline \multirow{2}{*}{ Date } & \multicolumn{4}{l}{ Increased length of root stock $(\mathbf{c m})$ at } \\
\cline { 2 - 5 } & 30 DAG & 60 DAG & 90 DAG & I 20 DAG \\
\hline I0-Mar & 46.61 & 58.49 & 65.83 & 73.86 \\
20-Mar & 47.15 & 58.59 & 66.03 & 74.34 \\
30-Mar & 47.35 & 58.79 & 66.23 & 74.54 \\
10-Apr & 47.73 & 59.17 & 66.61 & 74.92 \\
20-Apr & 47.77 & 59.21 & 66.64 & 74.97 \\
30-Apr & 47.51 & 58.92 & 66.41 & 74.72 \\
10-May & 47 & 58.85 & 66.27 & 74.65 \\
20-May & 47.51 & 58.95 & 66.38 & 74.71 \\
30-May & 46.66 & 58.54 & 65.91 & 74.13 \\
LSD at 5\% & 1.026 & 0.047 & 0.239 & 0.04 \\
LSD at I\% & 1.352 & 0.062 & 0.315 & 0.053 \\
Level of significant & $\mathrm{NS}$ & $* *$ & $* *$ & $* *$ \\
\hline
\end{tabular}

$* *=1 \%$ level of probability, NS= Not significant, DAG = Days after grafting

\section{Main effect of varieties}

The data showed that the varieties on the rootstock length had significant effect on the increased length of rootstock which was recorded at $120 \mathrm{DAG}$. The highest increased rootstock length $(75.17 \mathrm{~cm})$ was given by BAU Aam- 6 followed by BAU Aam $-7(75.06 \mathrm{~cm}) \mathrm{cm}$ and the lowest $(73.80 \mathrm{~cm})$ was in BAU Aam-13 (Table 8$)$.
Table 8 Main effect of varieties on increased length of rootstock

\begin{tabular}{lllll}
\hline \multirow{2}{*}{ Variety } & \multicolumn{4}{l}{ Increased length of rootstock $(\mathbf{c m})$ at } \\
\cline { 2 - 5 } & 30 DAG & 60 DAG & 90 DAG & I 20 DAG \\
\hline BAU Aam-I & 47.17 & 59 & 66.42 & 74.8 \\
BAU Aam-2 & 46.84 & 58.75 & 66.17 & 74.45 \\
BAU Aam-3 & 47.26 & 59.02 & 66.37 & 74.7 \\
BAU Aam-4 & 50.77 & 58.57 & 65.86 & 74.26 \\
BAU Aam-5 & 46.89 & 58.96 & 66.41 & 74.68 \\
BAU Aam-6 & 47.66 & 59.43 & 66.81 & 75.17 \\
BAU Aam-7 & 47.45 & 59.35 & 66.7 I & 75.06 \\
BAU Aam-8 & 47.37 & 59.23 & 66.64 & 75.02 \\
BAU Aam-9 & 46.95 & 58.88 & 66.26 & 74.38 \\
BAU Aam-10 & 46.44 & 58.38 & 66.55 & 74.13 \\
BAU Aam-1I & 46.75 & 58.68 & 66.02 & 74.37 \\
BAU Aam-12 & 46.54 & 58.47 & 65.7 I & 74.19 \\
BAU Aam-13 & 46.21 & 58.13 & 65.43 & 73.8 \\
LSD at 5\% & 1.233 & 0.056 & 0.287 & 0.048 \\
LSD at I\% & 1.625 & 0.074 & 0.379 & 0.063 \\
Level of significant & $* *$ & $* *$ & $* *$ & $* *$ \\
\hline
\end{tabular}

$* *=1 \%$ level of probability, DAG = Days after grafting

\section{Combined effect of time of grafting and varieties on rootstock length}

The different time of grafting operation and varieties had significant combined effect on the increased length of rootstock at 30 to 120 DAG. The highest length of rootstock $(75.56 \mathrm{~cm})$ was recorded in 10 April and 20 April operation with BAU Aam- 6 and the lowest $(72.10 \mathrm{~cm})$ was noted in 10 March operation with BAU Aam-9 at 120 DAG. These results indicated that the variation in rootstock length might be due to cumulative effect of time of grafting operation and varieties. During April, favorable environmental condition prevailed which was helpful for growth of rootstock.

\section{Effect of time of grafting operation and varieties on scion length}

The increase in scion length for all assigned treatments was measured periodically giving 30 days interval and continued up to 120 days after grafting. It was found that varieties and time of grafting significantly influenced $(\mathrm{P}<0.01)$ on the increase in scion length at every date of measurement.

\section{Main effect of time of grafting operation}

The periodically recorded data on the increment of scion length envisaged that there was an ample influence of different time of grafting operations on scion length. A linear growth of new scion shoot was found with the advancement of time. The 20 April grafting operation showed the maximum growth. ${ }^{32}$ This might be due to prevailing congenial climatic condition along with availability of dormant and swollen terminal buds of scion in budding condition, which encouraged earlier sprouting and their continual growth. The10 March grafted plants showed the lowest increase in scion length. After 120 days of grafting operation, the highest scion length $(16.43 \mathrm{~cm})$ was found in 20 April grafted plants while the lowest was recorded in case of 20 March grafted 
plants $(15.84 \mathrm{~cm})$. The result might be due to the variation in environmental condition. As the extremity of either direction of temperature or humidity is harmful for normal growth and development of plants, thus the April grafted plants might have not performed better. However, the growth rate of the scion was seen in accordance with the raising in temperature and increased humidity. ${ }^{33}$

\section{Main effect of varieties}

Varieties had significant effect on the length of scion at 30,60 , 90 and 120 DAG (Tables $9 \& 10)$. The highest $(16.90 \mathrm{~cm})$ length of scion was observed in BAU Aam-7 followed by BAU Aam-6 $(16.89 \mathrm{~cm})$ and the lowest $(15.19 \mathrm{~cm})$ was in BAU Aam-13 followed by BAU Aam-12 $(15.62 \mathrm{~cm})$. There was significant variation in combined effect of time of grafting operation and variety at 30 to $120 \mathrm{DAG}$. The highest (17.18) was in 10 and 20 April grafting with BAU Aam-6 and the lowest $(14.77 \mathrm{~cm})$ increased scion length was noted in 20 March grafting operation with BAU Aam-13.

Table 9 Main effect of time of grafting operation on increased length of scion

\begin{tabular}{lllll}
\hline \multirow{2}{*}{ Date } & \multicolumn{4}{l}{ Increased length of scion $(\mathbf{c m})$ at } \\
\cline { 2 - 5 } & 30 DAG & 60 DAG & 90 DAG & 120 DAG \\
\hline 10-Mar & 10.98 & 12.73 & 13.81 & 16.02 \\
20-Mar & 10.78 & 12.56 & 13.7 & 15.84 \\
30-Mar & 10.98 & 12.76 & 13.9 & 16.04 \\
I0-Apr & 11.36 & 13.14 & 14.28 & 16.42 \\
20-Apr & 11.37 & 13.17 & 14.28 & 16.43 \\
30-Apr & 11.1 & 12.89 & 14.02 & 16.18 \\
10-May & 11.1 & 12.88 & 14 & 16.15 \\
20-May & 11.11 & 12.91 & 14.02 & 16.17 \\
30-May & 11.04 & 12.84 & 13.91 & 16.13 \\
LSD at 5\% & 0.024 & 0.037 & 0.072 & 0.037 \\
LSD at I\% & 0.032 & 0.049 & 0.095 & 0.049 \\
Level of significance & $* *$ & $* *$ & $* *$ & $* *$ \\
\hline
\end{tabular}

$* *=1 \%$ level of probability, DAG $=$ Days after grafting

Table 10 Main effect of varieties on increased length of scion

\begin{tabular}{lllll}
\hline \multirow{2}{*}{ Variety } & \multicolumn{4}{l}{ Increased length of scion(cm) at } \\
\cline { 2 - 5 } & 30 DAG & 60 DAG & 90 DAG & I20 DAG \\
\hline BAU Aam-I & 11.36 & 13.01 & 14.26 & 16.52 \\
BAU Aam-2 & 10.85 & 12.95 & 13.94 & 15.94 \\
BAU Aam-3 & 11.42 & 13.13 & 14.18 & 16.67 \\
BAU Aam-4 & 10.76 & 12.76 & 13.86 & 15.78 \\
BAU Aam-5 & 11.26 & 12.99 & 14.19 & 16.38 \\
BAU Aam-6 & 11.78 & 13.1 & 14.38 & 16.89 \\
BAU Aam-7 & 11.64 & 13.1 & 14.38 & 16.9 \\
BAU Aam-8 & 11.62 & 13.08 & 14.37 & 16.66 \\
BAU Aam-9 & 11.15 & 12.89 & 14.01 & 16.28 \\
BAU Aam-10 & 10.48 & 12.56 & 13.48 & 15.32 \\
BAU Aam-1 I & 10.88 & 12.85 & 13.85 & 15.87 \\
BAU Aam-12 & 10.66 & 12.64 & 13.64 & 15.62 \\
\hline
\end{tabular}

\begin{tabular}{lllll} 
Table Continues... & \multicolumn{4}{l}{ Increased length of scion(cm) at } \\
\cline { 2 - 5 } Variety & 30 DAG & 60 DAG & 90 DAG & I 20 DAG \\
\hline BAU Aam-13 & 10.31 & 12.36 & 13.37 & 15.19 \\
LSD at 5\% & 0.029 & 0.045 & 0.086 & 0.045 \\
LSD at I\% & 0.039 & 0.059 & 0.114 & 0.059 \\
Level of significant & $* *$ & $* *$ & $* *$ & $* *$ \\
\hline
\end{tabular}

$* *=1 \%$ level of significance, $D A G=$ Days after grafting

\section{Conclusion}

This study aimed to assess the effects of grafting time on the success and survivability of different varieties of mango at the FTIP (Fruit Tree Improvement Project), Department of Horticulture, Bangladesh Agricultural University. The mean differences (LSD) test Analysis from grafted plants and its component in respect of grafting time and variety revealed considerable variability for most of the traits. The minimum time required to bud breaking ( 9.44 days) for 30 April followed by 10 May (9.45days) grafted plants while it was maximum (12.14 days) was noted in 10 March grafted plants followed by 20 March (11.27) and 30 March (11.47). The highest success in grafting was recorded in 20 April (96.87\%) followed by 10 April (96.81\%). The lowest graft success was observed in 10 March (96.05\%) followed by 20 March (96.23\%) grafting operation. The highest survivability in grafting operation was recorded in 20 April (90.62\%) operation followed by 10 April $(90.51 \%)$ and lowest graft survivability was observed in 10 March (88.64 \%) grafting operation followed by 20 April (89.93\%). The maximum increased stionic height $(66.16 \mathrm{~cm})$ was recorded in case of 20 April operation, while the minimum $(65.07 \mathrm{~cm})$ was in 10 March operation. The minimum time (9.46 days) required for bud breaking was found in BAU Aam-6 followed by BAU Aam-7 (9.72 days) and the maximum (11.64 days) and was required in BAU Aam-10 followed by BAU Aam-13 (11.64days) and BAUAam-12 (11.57 days). The highest graft success (97.3\%) was achieved in BAU Aam- 6 followed by BAU Aam-8 (96.95\%) and the lowest (95.66) was in BAU Aam-13 followed by BAU Aam-12 (95.79\%). The maximum graft survivability $(96.23 \%$ ) was observed in BAU Aam-6 followed by BAU Aam-7 (94.97\%) and the minimum $(86.42 \%)$ was found in BAU Aam-13 followed by BAU Aam-12 (86.61\%). The highest increased stionic height $(79.14 \mathrm{~cm})$ was observed in BAU Aam-6 at 120 DAG and the lowest increased stionic height $(60.19 \mathrm{~cm})$ was in B AU A a m13. The highest $(16.90 \mathrm{~cm})$ increased length of scion was observed in BAU Aam-7 followed by BAU Aam $-6(16.89 \mathrm{~cm})$ and the lowest $(15.19 \mathrm{~cm})$ was in BAU Aam-13 followed by BAU Aam-12 $(15.62 \mathrm{~cm})$. In case of combined effect, the minimum time ( 7.73 days) was required in BAU Aam- 6 in 30 April grafting while the maximum time (13.06 days) required for bud breaking was observed in BAU Aam -10 when the grafting operation was done in 10 March. Grafting operation done in 10 April and 20 April with the scion of BAU Aam-1 gave the highest success (97.64\%) followed by 10 April and 20 April with the scion of BAU Aam-7 (97.47\%) and the lowest (94.81\%) was in 10 March with BAU Aam-7 followed by 30 May with the scion of BAU Aam-7 (94.91\%).

\section{Acknowledgments \\ None.}

\section{Conflicts of interest}

The author declares there is no conflict of interest. 


\section{References}

1. Mahesh S, Kulapati Hipparagi, Balesh Goudappanavar, et al. Influence of Different Mango Varieties and Time of Grafting on Graft Survivability (\%) in Both Polyhouse and Shade Net Under Northrn Dry Zone of Karnataka. Int J Pure Appl Biosci. 2018;5(5):1445-1451.

2. Islam MN, Rahim MA, Farooque AM. Standardization of time and grafting techniques in Mango under Bangladesh condition. Asian J Plant Sci. 2004;3(3):378-386.

3. BBS. Statistical Pocket Book Bangladesh 2017. 2017.

4. Ali MA, Islam MS, Sarker MNI, et al. Study on Biology of Red Pumpkin Beetle in Sweet Gourd Plants. Int J Appl Res. 2015;2:1-4.

5. Ali MA, Islam MS, Sarker MNI. Effect of seed borne fungi on germinating wheat seed and their treatment with chemicals. Int J Nat Soc Sci. 2015;2:28-32.

6. Sarker MNI. Poverty of Island Char Dwellers in Bangladesh. 2016.

7. Sarker MNI, Barman SC, Islam MM, et al. Role of lemon (Citrus limon) production on livelihoods of rural people in Bangladesh. J Agric Econ Rural Dev. 2017;3(1):167-175.

8. Prodhan AS, Sarker MNI, Sultana A, et al. Knowledge,adoption and attitude on banana cultivation technology of the banana growers of Bangladesh. Int J Hortic Sci Ornam Plants. 2017;3:47-52.

9. Sarker MNI. An Introduction to Agricultural Anthropology: Pathway to Sustainable Agriculture. J Sociol Anthropol. 2017;1(1):47-52.

10. Sarker MNI, Jie Z. Social Security for Vulnerable Groups in Bangladesh on Government Perspective: Contribution of Research Leader. J Public Policy Adm. 2017;1(1):1-9.

11. Karna AK, Varu DK, Kumar Patel M, et al. Effect of Grafting Time on Success of Softwood Grafting in Mango (Mangifera indica L.). Int J Curr Microbiol Appl Sci. 2018;7(8):3072-3077.

12. Sarker MNI, Sultana A. An Investigation into the Status of Riverbank (Char) Women Dwellers in Bangladesh. Int J Rural Dev Environ Heal Res. 2017;1(1):86-92.

13. Nasrin M, Sarker MNI, Huda N. Determinants of health care seeking behavior of pregnant slums dwellers in Bangladesh. Med Sci. 2019;23:3541 .

14. Sarker MNI. Role of Banks on Agricultural Development in Bangladesh. Int J Ecol Dev Res. 2016;1(1):10-15.

15. Prasanth J, Reddy P, Patil S, et al. Effect of cultivars and time of softwood grafting on graft success and survival in mango. Agric Sci Dig. 2007;27(1):18-21.

16. Ali MA, Islam MS, Sarker MNI. Efficacy of medicinal plants against seed borne fungi of wheat seeds. Int J Nat Soc Sci. 2015;2(1):48-52.

17. Sarker MNI. Knowledge, Adoption and Constraint analysis of Chilli Technology in Char Area of Bangladesh. Int J Ecol Dev Res. 2016;1(1):1618
18. Amin MAl, Sarker MNI, Hossin MA, et al. Cigarette Selling and Buying by the Minor and Adolescents in Bangladesh: Prevalence, Perceptions and Awareness. J Soc Sci Res. 2018;4(12):556-570.

19. Haider MK, Islam MS, Islam SS, et al. Determination of crop coefficient for transplanted Aman rice. Int J Nat Soc Sci. 2015;2:34-40.

20. Ali MA, Islam MS, Sarker MNI, et al. Feeding Behavior and Food Preference of Red Pumpkin Beetle, Aulacophora Foveicollis. Am J Plant Biol. 2016;1(1):13-17.

21. Islam MS, Khanam MS, Sarker MNI. Health risk assessment of metals transfer from soil to the edible part of some vegetables grown in Patuakhali province of Bangladesh. Arch Agric Environ Sci. 2018;3(2):187-197.

22. Rashid MH, El Taj HF, Jung C. Life-table study of mango leaf cutting weevil, Deporaus marginatus Pascoe (Coleoptera: Curculionidae) feeding on four mango cultivars. J Asia Pac Entomol. 2017;20(2):353-357.

23. Sarker MNI. Causes and possible solutions of seasonal food insecurity (Monga) perceived by char dwellers in Bangladesh. Int J Ecol Dev Res. 2016;1(1):2-9.

24. Islam MS, Ram Proshad, MA Hoque, et al. Assessment of heavy metals in foods around the industrial areas: Health hazard inference in Bangladesh. Geocarto Int. 2018;33:1016-1045.

25. Koepke T, Dhingra A. Rootstock scion somatogenetic interactions in perennial composite plants. Plant Cell Rep. 2013;32(9):1321-1337.

26. Rathore AC, PL Saroj, H Lal, et al. Performance of mango based agrihorticultural models under rainfed situation of Western Himalaya, India. Agrofor Syst. 2013;87(6):1389-1404.

27. Karimi HR, Nowrozy M. Effects of rootstock and scion on graft success and vegetative parameters of pomegranate. Sci Hortic. 2017;214:280-287.

28. Sarker MNI, Wu M, Alam GM, et al. Livelihood Vulnerability of Riverine-Island Dwellers in the Face of Natural Disasters in Bangladesh. Sustainability. 2019;11(6):1-23.

29. Sarker MNI, Wu M, Shouse RC, et al. Administrative Resilience and Adaptive Capacity of Administrative System: A Critical Conceptual Review in Lecture Notes on Multidisciplinary Industrial Engineering. 2019.

30. Akher SA, Sarker MNI, Naznin S. Salt stress mitigation by salicylic acid in wheat for food security in coastal area of Bangladesh. J Plant Stress Physiol. 2018;4:7-16.

31. Sarker MNI, Wu M. Bureaucracy in Bangladesh: A Disaster Management Perspective. 2019.

32. Deependra Yadav, Singh SP. Mango: History origin and distribution. $J$ Pharmacogn Phytochem. 2017;6(6):1257-1262.

33. Galdino TVDS, Sunil Kumar, LS Oliviera, et al. Mapping Global Potential Risk of Mango Sudden Decline Disease Caused by Ceratocystis fimbriata. PLoS One. 2016;11:159450. 